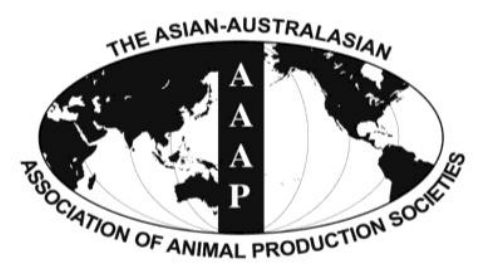

Asian Australas. J. Anim. Sci.

Vol. 26, No. 5 : 716-722 May 2013

http://dx.doi.org/10.5713/ajas.2012.12525

Www.ajas.info

pISSN $1011-2367$ elSSN 1976-5517

\title{
Variation of Meat Quality Parameters Due to Conformation and Fat Class in Limousin Bulls Slaughtered at 25 to 27 Months of Age
}

\author{
Dominika Guzek $^{1}{ }^{1}$, Dominika Gląbska ${ }^{2}$, Grzegorz Pogorzelski ${ }^{1}$, Karolina Kozań ${ }^{1}$, Jacek Pietras ${ }^{1}$, \\ Malgorzata Konarska ${ }^{1}$, Anna Sakowska ${ }^{1}$, Krzysztof Gląbski ${ }^{3}$, Ewelina Pogorzelska ${ }^{1}$, \\ Jerzy Barszczewski ${ }^{4}$ and Agnieszka Wierzbicka ${ }^{1}$ \\ ${ }^{1}$ Division of Engineering in Nutrition, Faculty of Human Nutrition and Consumer Sciences, \\ Warsaw University of Life Sciences (WULS - SGGW), Nowoursynowska str. 159C, 02-776 Warsaw, Poland
}

\begin{abstract}
The aim of the present study was to determine the influence of age of animal, hot carcass weight, pH, conformation and fat class on basic beef quality attributes (tenderness, sarcomere length, basic chemical composition, marbling and colour) in a group of purebred animals. The object of the study was beef of Limousin bulls (25 to 27 months, hot carcass weight - 432 $\pm 31 \mathrm{~kg}$, "U" conformation class, "2"-“3" fat class). Analysed cuts were Infraspinatus muscle from the blade and Longissimus dorsi muscle from the cube roll and the striploin. Tenderness was analysed with universal testing machine, colour - chromometer analysis, sarcomere length microscopic method, basic chemical composition - near-infrared spectroscopy and marbling - computer image analysis. No differences in tenderness and sarcomere length were observed within the age groups of Limousin bulls (age of 25, 26, 27 months) ( $\mathrm{p}>0.05$ ). Moisture $(\mathrm{p}=0.0123)$ and fat $(\mathrm{p}=0.0250)$ content were significantly different for meat of animals slaughtered at the age of 25 and 27 months. No influence of $\mathrm{pH}$ value on tenderness was observed, but at the same time, influence on sarcomere length $(\mathrm{p}=0.039)$ and $\mathrm{b}^{*}$ component of colour (0.045) was found. For "U" conformation class, in subclasses, as well as for fat classes "2"-" 3 ", there were no differences in tenderness, sarcomere length and colour components. Higher fat content was observed in the higher fat class, rather than in lower, however this feature was not associated with marbling. (Key Words: Beef Quality, Conformation, Fat Class, Chemical Composition, Tenderness, Sarcomere)
\end{abstract}

\section{INTRODUCTION}

Beef meat characteristics, such as meat tenderness, colour and marbling (intramuscular fat quantity) are important factors which establish meat quality perceived by consumers, and as a consequence shape market demand. The structure of muscle, including intrinsic structure (sarcomere length, myofilament diameter, fiber types) and its basic chemical composition (moisture, fat, protein, ash

\footnotetext{
* Corresponding Author: Dominika Guzek. Tel: +48-22-5937078, Fax: +48-22-5937060, E-mail: dominika_guzek@sggw.pl

2 Department of Dietetics, Faculty of Human Nutrition and Consumer Sciences, Warsaw University of Life Sciences (WULS - SGGW), 02-776 Warsaw, Poland

3 Department of Microbial Biochemistry, Institute of Biochemistry and Biophysics, Polish Academy of Sciences (PAS PAN), 02-106 Warsaw, Poland

${ }^{4}$ Grasslands Division, Institute of Technology and Life Sciences in Falenty (ITLS - ITP), 05-090 Raszyn, Poland Submitted Sept. 21, 2012; Accepted Dec. 2, 2012; Revised Jan. 11, 2013
}

and collagen content) are also important, because meat quality depends on them. Beef quality may be partly explained by understanding of these factors. The strongest single beef quality attribute is the marbling score, so in many countries it is the basis for the carcasses evaluation (Hocquette et al., 2005), e.g. it is the major factor in determination of beef "quality grade" in USA (Indurain et al., 2009). However, in European countries, evaluation of meat quality is based only on conformation and fat EUROP classification. It is concluded that there is a positive relationship between marbling score and quality grade, while there is weaker relationship between maturity score and quality grade (Park et al., 2002). On the other hand, it is suggested, that when animal is getting older, marbling score is increasing, but tenderness is decreasing (Wulf et al., 1996). Simultaneously, the most variable factors in the meat production, even in similar conditions, that may also influence meat quality, are the weight of animal and $\mathrm{pH}$ of meat. All the mentioned factors contribute to meat quality, however it is still not well known if it is possible to create 
meat quality and specified desired quality traits, by planning conformation and fat class of carcasses during production accompanied by controlling weight of animal and age of slaughter.

The aim of the present study was to determine the influence of age of animal, hot carcass weight, $\mathrm{pH}$, conformation and fat class on basic beef quality attributes (tenderness, sarcomere length, basic chemical composition, marbling and colour), that was analysed on a small homogenous group of purebred animals.

\section{MATERIAL AND METHODS}

\section{Sample preparation}

The object of the study was beef of Limousin bulls characterized by hot carcass weight of $432 \pm 31 \mathrm{~kg}$ (388 to $466 \mathrm{~kg}$ ), "U" conformation class and " 2 "-" 3 " fat class. Animals were raised using typical practices, dam-reared to the age of natural weaning ( 8 to 9 months) and after that raised on natural pastures. No feeding supplementation was applied. All the animals were slaughtered at the age of 25 to 27 months. Carcasses were aged at $4^{\circ} \mathrm{C}$ for 5 days post mortem. The range of $\mathrm{pH}$ values was typical $(5,48$ to 5,87$)$ no defects of carcasses were observed. Cuts (3 to 9 for each group) were obtained from each carcass - it was Infraspinatus muscle from the blade (slow twitch oxidative fibers - type I) and Longissimus dorsi muscle (fast twitch glycolytic fibers - type IIB) from the cube roll and the striploin. As Longissimus dorsi is the longest muscle in beef cattle, it was decided to analyse two cuts within this muscle - anterior and posterior (Longissimus dorsi et thoracis and Longissimus dorsi et lumborum). Cuts were obtained from a commercial abattoir without an excessive amount of intramuscular fat tissue and connective tissue.

\section{Texture analysis}

After slaughter, the meat was aged for $5 \mathrm{~d}$ to $2 \mathrm{~d}$ in carcasses and afterwards $3 \mathrm{~d}$ in steaks in a vacuum at a temperature of $0^{\circ} \mathrm{C}$. After ageing, steaks were stored in a vacuum at a temperature of $-18^{\circ} \mathrm{C}$. For texture analysis (Warner-Bratzler shear force), the representative beef steaks were thawed in a refrigerator until an internal temperature of $2^{\circ} \mathrm{C}$ was reached. Thermal treatment was conducted using Silex High Speed Contact Grill S-165K (Silex Grills, Stanmore, Australia) until an internal temperature of $71^{\circ} \mathrm{C}$ was reached, according to widely applied methodology (AMSA, 1995). After thermal treatment steaks were chilled at $2 \pm 1{ }^{\circ} \mathrm{C}$ before coring to obtain uniform diameter cores. Six $1.27-\mathrm{cm}$ cores were sheared once perpendicular to the longitudinal orientation of the muscle fibers with a Instron 4301 Universal Testing Machine (Instron, Canton, Massachusetts, USA) equipped with a $500 \mathrm{~N}$ load cell and $\mathrm{V}$-notch blade with a cut rate of $200 \mathrm{~mm} / \mathrm{min}$ was used. The tenderness of samples [N] was recorded as the first significant peak of the force-deformation curve (where the force falls off).

\section{Sarcomere length measurement}

Sarcomere length was measured according to the method of Cross et al. (1981) with some modifications (quantity of myofibrils and sarcomeres measured was modified to allow obtaining representative results), as published previously (Guzek et al., 2012). For each cut, representative $5 \mathrm{~g}$ meat samples were collected and microscopic preparations were obtained from a sucrose solution - samples were homogenized in $30 \mathrm{ml}$ of cold 0.25 M sucrose at low speed (mechanical homogeniser PRO 200, PRO Scientific Inc., Connecticut, USA - 5,000 rpm, 60 seconds). The evaluation of the sarcomere length was conducted using a Carl Zeiss Axio Imager.M2 microscope (Carl Zeiss, Oberkochen, Germany) with the EC PlanNeofluar 100x/1.30 Oil Ph 3 M27 objective and AxioCamMR5 camera. Microscopic preparations were observed under DIC - differential interference contrast. Sarcomere length was measured using the AxioVision Rel.4.8.2 software (Carl Zeiss, Oberkochen, Germany). Three myofibrils were selected for every sample and length of 25 sarcomeres for each myofibril was measured.

\section{Basic chemical composition measured using near- infrared spectroscopy (NIR)}

For each cut, representative $150 \mathrm{~g}$ meat samples were collected and homogenized with a blender for at least 30 seconds, but no longer than $60 \mathrm{~s}$, in order to obtain a homogenous mixture. Samples were placed on petri dish (diameter - $90 \mathrm{~mm}$ ) in NIR device (NIR Flex Solids N-500, Büchi, Flawil, Switzerland - spectral range - 800 to 2,500 $\mathrm{nm})$. For each sample, scanning with spectrophotometer was performed three times, according to widely applied methodology (Prevolnik et al., 2004). Spectral analysis software NIR Ware 1.1, NIR Cal 5.1 (Büchi, Flawil, Switzerland) was used. Moisture, fat, protein, ash and collagen content $(\%)$ was measured for each sample.

\section{Intramuscular fat tissue measured using computer image analysis}

Intramuscular fat tissue quantity (marbling) (\%) for each meat sample was determined using computer image analysis, according to widely applied methodology (Yang et al., 2006). The representative beef steaks, after blooming for half an hour, were placed on a matt green background to ensure easier segmentation. The pictures of beef steaks were taken using CD QImaging MicroPublisher 5.0 RTV camera (QImaging, Surrey, Canada) under fluorescent light in standard conditions (colour temperature of $5400 \mathrm{~K}$ similar to sunlight). Each image was captured and saved in 
TIFF format. The area of intramuscular fat tissue was calculated using Image-Pro Plus 7 (Media Cybernetics, Silver Spring, Maryland, USA).

\section{Components of colour analysis}

The colour of meat samples was measured using a Hunter Lab chromometer Minolta CR-400 (Minolta Camera Co., Osaka, Japan) with an $8 \mathrm{~mm}$ diameter measurement area, using a D65 standard illuminant. The chromometer was previously calibrated against a standard white reference tile (CR-A43). Ten measurements were taken for each sample in various steak locations, with the exception of marbling areas, according to recommended methodology (Hunt et al., 1991). The L* (lightness), a* (bluish-green/ red-purple hue component) and $\mathrm{b}^{*}$ (yellow/blue hue component) values were collected for all the samples.

\section{Statistical analysis}

To verify the normality of distribution the W ShapiroWilk test was used. Differences between the characteristics of analysed samples were assessed using t-Student test (in case of normal distribution) or U Mann-Whitney test (in case of distribution different from normal), as age, conformation class and fat class in some groups were not independent variables. Analysis of correlation for the characteristics of analysed samples was conducted using Pearson's correlation (in case of normal distribution) or Spearman's rank correlation (in case of distribution different from normal). Level of significance $\mathrm{p} \leq 0.05$ was used, but for the samples comparisons and correlations of characteristic of analysed samples, level $\mathrm{p} \leq 0.1$ was also indicated as close to significance. Statistical analysis was conducted using Statistica software version 8.0 (StatSoft, Tulsa, Oklahoma, USA).

\section{RESULTS AND DISCUSSION}

Attributes, such as meat tenderness, colour and fat tissue characteristics, as well as structure of muscle and basic chemical composition are important factors influencing meat characteristics. However, to understand associations between these factors, not only is research comparing features between various feeding systems and breeds required (Dymnicka et al., 2004; Nuernberg et al., 2005; Scollan et al., 2006; Xie et al., 2012), but also between age groups, conformation or fat classes.

Tenderness, sarcomere length, basic chemical composition and components of colour in the age groups did not differ in many cases. Differences were observed for moisture (Figure 1), fat (Figure 2) and collagen content (Figure 3), as well as for the $\mathrm{a}^{*}$ component of colour (Figure 4). It may be concluded that no differences in tenderness and sarcomere length were obzserved in the age

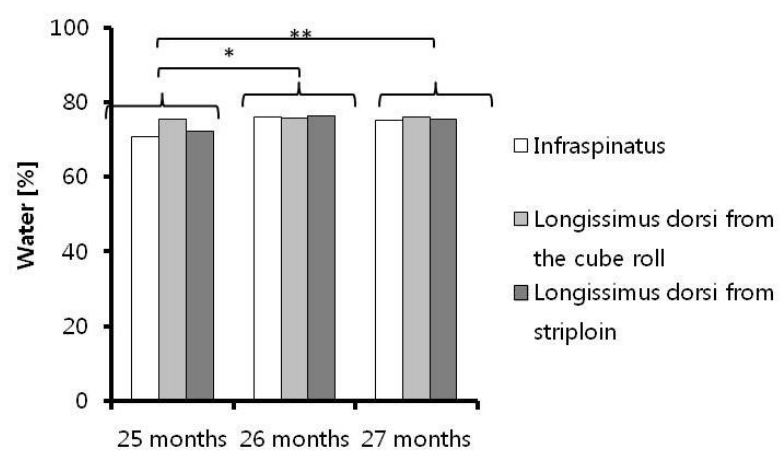

Figure 1. The water content $(\%)$ within the age groups for analysed muscles. $* \mathrm{p}<0.1$ - close to significance, $* * \mathrm{p}<0.05$ significance level (verification on the basis of t-Student test).

groups of Limousin bulls slaughtered at the age of 25 to 27 months ( $p>0.05)$. It is consistent with previous observations (Shackelford et al., 1995). Significant influence of age on basic chemical composition and meat colour, which was observed, is consistent with the statement that meat colour is influenced by carcass fatness, $\mathrm{pH}$ value, age and intramuscular fat content (Priolo et al., 2001).

In case of basic chemical composition, such as moisture $(\mathrm{p}=0.0123)$, fat $(\mathrm{p}=0.0250)$ and collagen content $(\mathrm{p}=$ 0.0901), significant $(\mathrm{p} \leq 0.05)$ or close to significance $(\mathrm{p} \leq 0.1)$ differences for beef meat of animals slaughtered at the age of 25 and 27 months were observed. Meat of younger Limousin bulls was characterized by lower moisture content and higher fat and collagen content. Observations are consistent with the conclusion that age has a great influence on meat quality, even greater than breed (du Plessis and Hoffman, 2007). On the other hand, research of other authors indicates that fat content in beef meat of animals slaughtered at the age of 18 months does not differ in case of various breeds (Muchenje et al., 2009).

Close to significance difference observed in case of moisture content for 25 and 26 months bulls suggests that for animals slaughtered at the age of 25 months, in comparison to other age groups, moisture content was lower

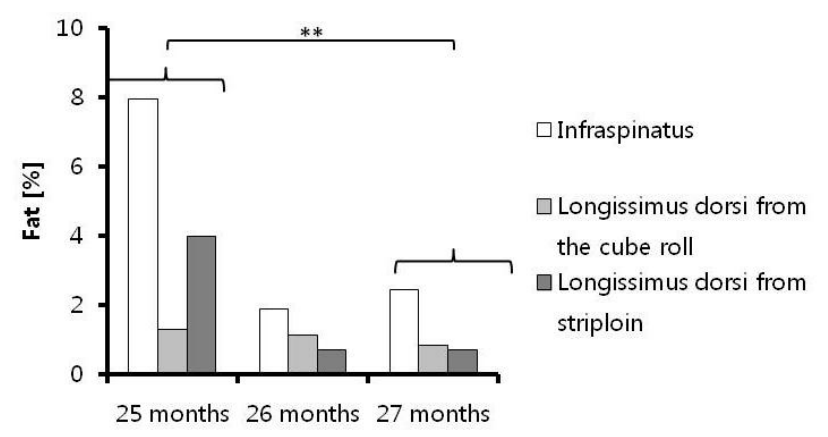

Figure 2. The fat content (\%) within the age groups for analysed muscles. $* * \mathrm{p}<0.05$ - significance level (verification on the basis of t-Student test). 


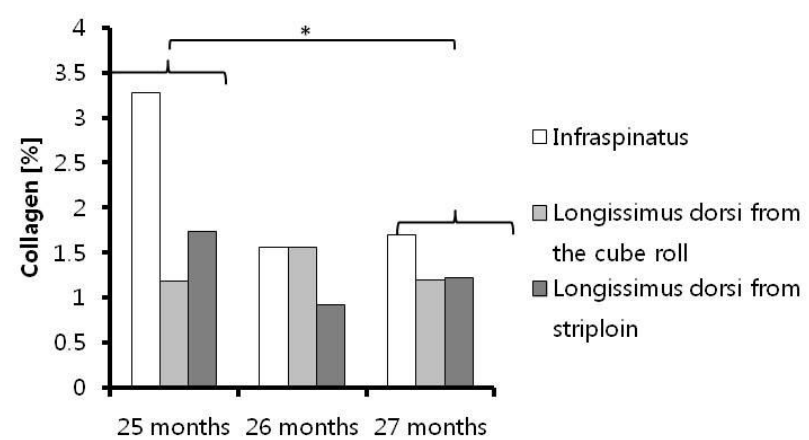

Figure 3. The collagen content $(\%)$ within the age groups for analysed muscles. * $\mathrm{p}<0.1$ - close to significance level (verification on the basis of U Mann-Whitney test).

than for older animals $(p=0.0882)$. In spite of fat content differences, no marbling differences were observed. This result may be connected with the fact that fat cover differences are not associated with changes in intramuscular fat quantity as indicated by Jones et al. (1992) from their observations that only 1 to $3 \%$ of the marbling variation is accounted by the subcutaneous fat thickness.

In case of $\mathrm{L}^{*} \mathrm{a} * \mathrm{~b} *$ components of colour, differences close to significance $(p=0.0710)$ for age groups were observed only in $\mathrm{a}^{*}$ component for animals slaughtered at the age of 26 and 27 months. Older animals were characterized by lower values of $\mathrm{a}^{*}$ component of colour (lower intensity of red colour). It is confirmed by observations of other authors, that a less red colour of meat (lower values of $\mathrm{a}^{*}$ component of colour) is obtained from older bulls rather than from younger (Weeglarz, 2010).

Analysis of correlation of hot carcass weight and $\mathrm{pH}$ of raw beef meat with tenderness, sarcomere length, basic chemical composition and components of colour is presented in Table 1. No influence of $\mathrm{pH}$ on tenderness was

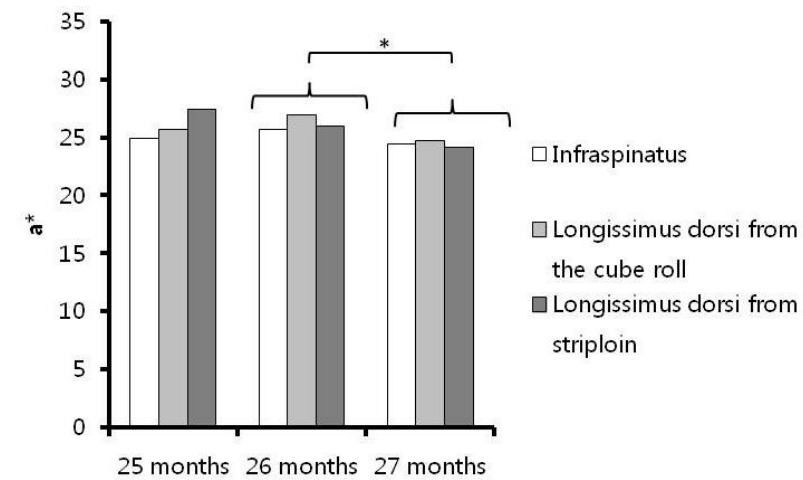

Figure 4. The $a^{*}$ component of colour within the age groups for analysed muscles. * $\mathrm{p}<0.1$ - close to significance level (verification on the basis of t-Student test).

observed, but at the same time, influence on sarcomere length, marbling score and colour (b*) was found. Simultaneously, it may be concluded that in case of Limousin bulls slaughtered at the age of 25 to 27 months, hot carcass weight does not influence any of analysed beef features. Also other authors conclude, that slaughter weight does not influence fatty acid profile of meat (Holló et al., 2001a), however, in some research they indicate an influence on monounsaturated fatty acids (Holló et al., 2001b).

In sarcomere length $(\mathrm{p}=0.039 ; \mathrm{R}=0.5354)$ and marbling $(p=0.080 ; R=0.4654)$, a positive correlation with $\mathrm{pH}$ was observed - for sarcomere length it was significant and for intramuscular fat quantity it was close to significance. It may be stated, that in case of higher $\mathrm{pH}$, beef meat is characterized by longer sarcomeres and this fact may influence general beef quality, including texture (Wheeler et al., 2000; Maher et al., 2005), however, no correlation between $\mathrm{pH}$ and meat tenderness was observed.

Table 1. Analysis of correlation of hot carcass weight and $\mathrm{pH}$ of raw beef meat with tenderness, sarcomere length, basic chemical composition and components of colour

\begin{tabular}{|c|c|c|c|c|c|}
\hline & & \multicolumn{2}{|c|}{ Hot carcass weight } & \multicolumn{2}{|c|}{$\mathrm{pH}$} \\
\hline & & $\mathrm{p}$ & $\mathrm{R}$ & $\mathrm{p}$ & $\mathrm{R}$ \\
\hline \multicolumn{2}{|l|}{ Tenderness $(\mathrm{kN})$} & $0.560^{\mathrm{a}}$ & 0.1637 & $0.741^{\mathrm{a}}$ & -0.0931 \\
\hline \multicolumn{2}{|l|}{ Sarcomere length $(\mu \mathrm{m})$} & 0.284 & 0.2958 & $0.039^{\mathrm{a}} * *$ & 0.5354 \\
\hline \multirow{6}{*}{$\begin{array}{l}\text { Basic chemical } \\
\text { composition }(\%)\end{array}$} & Water & $0.969^{\mathrm{a}}$ & -0.0109 & $0.167^{\mathrm{a}}$ & 0.3760 \\
\hline & Fat & $0.670^{\mathrm{a}}$ & 0.1200 & $0.741^{\mathrm{a}}$ & -0.0931 \\
\hline & Protein & 0.303 & -0.2853 & $0.102^{\mathrm{a}}$ & -0.4387 \\
\hline & Ash & 0.452 & -0.2101 & $0.165^{\mathrm{a}}$ & 0.3773 \\
\hline & Collagen & $0.344^{\mathrm{a}}$ & 0.2628 & $0.879^{\mathrm{a}}$ & -0.0431 \\
\hline & Marbling & 0.992 & -0.0027 & $0.080^{\mathrm{a} *}$ & 0.4654 \\
\hline \multirow{3}{*}{$\begin{array}{l}\text { Components of colour } \\
(-)\end{array}$} & $\mathrm{L}^{*}$ & 0.347 & -0.2615 & $0.661^{\mathrm{a}}$ & 0.1235 \\
\hline & $a^{*}$ & 0.291 & 0.2921 & $0.233^{\mathrm{a}}$ & -0.3279 \\
\hline & $b^{*}$ & 0.915 & 0.0300 & $0.045^{\mathrm{a} *}$ & -0.5246 \\
\hline
\end{tabular}

${ }^{a}$ distribution of at least one of correlated features different than normal (verification on the basis of W Shapiro-Wilk test - $p \leq 0.05$ ).

$* \mathrm{p}<0.1$ - close to significance, $* * \mathrm{p}<0.05$ - significance level (verification on the basis of Pearson's correlation - in case of normal distribution, and of Spearman's rank correlation - in case of distribution different than normal). 
In components of colour, $\mathrm{b}^{*}$ component was significantly correlated with $\mathrm{pH}(\mathrm{p}=0.045 ; \mathrm{R}=-0.5246)$, but for other components such correlations were not observed.

All presented correlations were moderate ( $\mathrm{R}$ coefficient lower than 0.7 ), so it may be suggested that $\mathrm{pH}$ value is not the only factor influencing analysed beef features. This conclusion is supported by differences in beef quality within age groups presented previously, as well as differences in beef quality within conformation class groups and fat class groups presented below.

Tenderness, sarcomere length, basic chemical composition and components of colour in the conformation class groups did not differ in general. Also other authors conclude, that the conformation type of heifers did not differentiate the traits decisive for the meat quality (Nogalski and Pogorzelska, 2001). The only difference was observed for marbling (Figure 5). It was concluded that for "U-", "U" and "U+" conformation classes, there were no differences in tenderness, sarcomere length and components of colour.

Differences observed in marbling between "U-" and "U" samples were close to statistical significance ( $p=$ 0.0942). Samples from carcasses assessed as "U-" conformation class were characterized by higher quantity of intramuscular fat tissue than in case of samples from carcasses assessed as "U" conformation class. It may be concluded, that for Limousin bulls slaughtered at the age of 25 to 27 months, in "U" conformation subclasses, differences in beef meat characteristics are rather minor and conformation class does not influence meat quality. It has been previously suggested by other authors, that carcasses conformation class, as well as fat class are relatively poor predictors of carcass composition (Pabiou et al., 2011). Marbling is the only exception and it may be correlated with carcass classification (Janz et al., 2004).

Tenderness, sarcomere length, basic chemical composition and components of colour in the fat class groups did not differ in general, as was the case in the

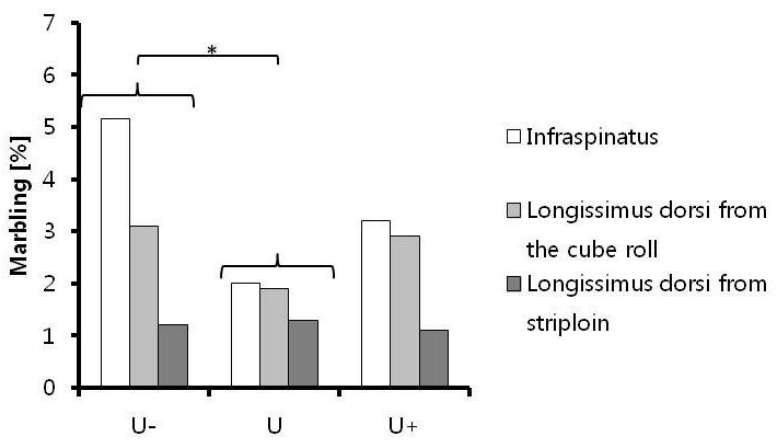

Figure 5. The marbling (\%) within the conformation class groups for analysed muscles. $* \mathrm{p}<0.1$ - close to significance level (verification on the basis of t-Student test)

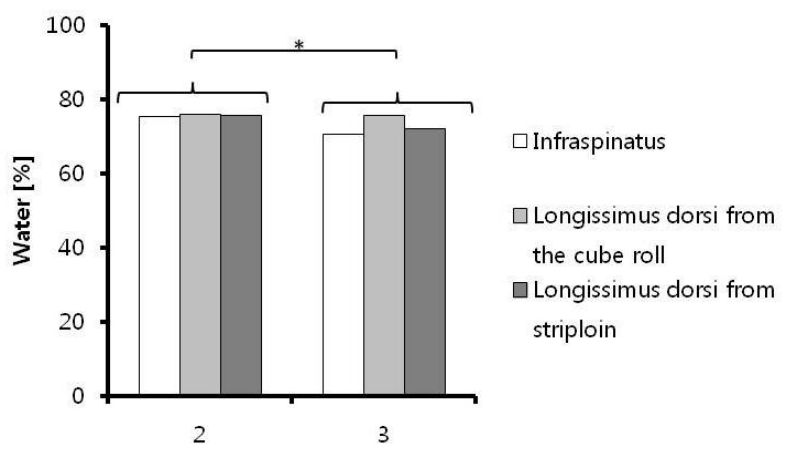

Figure 6. The water content $(\%)$ within the fat class groups for analysed muscles. * $\mathrm{p}<0.1$ - close to significance level (verification on the basis of U Mann-Whitney test).

conformation class groups. The differences were observed only for basic chemical composition: moisture (Figure 6), fat (Figure 7) and collagen content (Figure 8). It may be concluded, that in fat class range " 2 "-“ 3 ", fat class does not influence tenderness, sarcomere length and colour of beef from "U" conformation class Limousin bulls.

Beef meat from carcasses of class " 3 " was characterized by a higher fat content ( $p=0.0086)$ than class " 2 ". Simultaneously, class " 3 " was characterized by higher collagen quantity $(\mathrm{p}=0.0523)$ and lower moisture content ( $p=0.0513$ ), when compared to class " 2 ". No difference in marbling, observed at the same time, indicates that various fat classes were mainly associated with fat cover, not with intramuscular fat tissue quantity. Present observations support the breeding experiments conducted by Gwartney et al. (1996), indicating that it is possible to reduce carcass fatness (subcutaneous) while maintaining marbling and eating quality of beef.

\section{IMPLICATION}

It is important to evaluate the real influence of age of animal, hot carcass weight, $\mathrm{pH}$, conformation and fat class on quality attributes to create desired traits of beef. In the

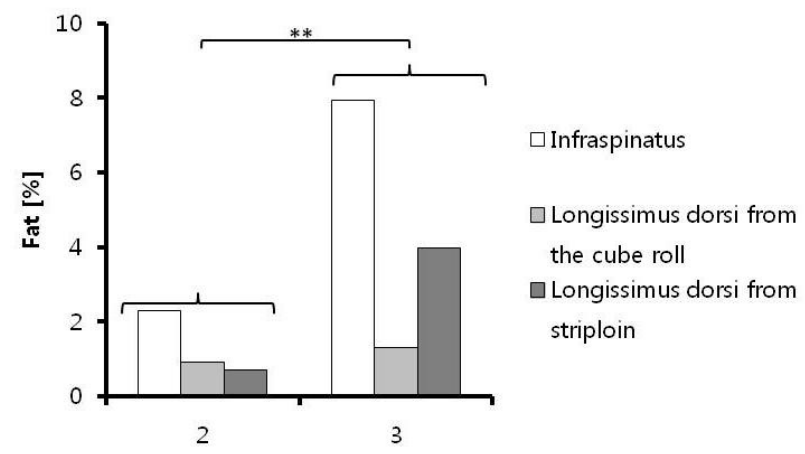

Figure 7. The fat content $(\%)$ within the fat class groups for analysed muscles. $* * \mathrm{p}<0.05$ - significance level (verification on the basis of t-Student test). 


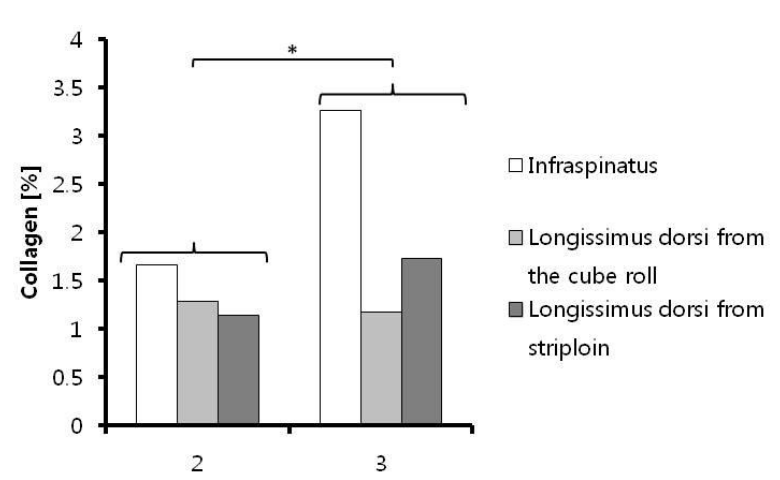

Figure 8. The collagen content (\%) within the fat class groups for analysed muscles. * $\mathrm{p}<0.1$ - close to significance level (verification on the basis of t-Student test).

age groups of Limousin bulls slaughtered at the age of 25 to 27 months, no differences in tenderness and sarcomere length were observed. Meat of younger bulls was characterized by lower moisture and higher fat content, but these factors were not associated with marbling. Hot carcass weight did not influence any of the analysed features. No influence of $\mathrm{pH}$ on tenderness was observed, but a positive correlation of $\mathrm{pH}$ with sarcomere length and negative with $b^{*}$ component of colour was found. For " $U$ " conformation class, in subclasses, as well as for fat classes " 2 "-“" 3 ", there were no differences in tenderness, sarcomere length and colour. Higher fat content was observed in the higher fat class than in the lower, however, it was not associated with marbling. By planning conformation and fat class during production combined with controlling weight and age of slaughter of Limousin bulls, it is possible to modify chemical composition and colour of meat, but for " $U$ " conformation and "2"-" 3 " fat classes, it is difficult to modify marbling and tenderness, even if sarcomere length is altered.

\section{ACKNOWLEDGEMENTS}

Research was supported by the Program "Improving Polish sources of plant protein, their production, trading and application in pasturages - Production of high-quality pasturages from the permanent pastures" (longstanding program for ages 2011-2015) - "Ulepszanie krajowych źródeł białka roślinnego, ich produkcji, systemu obrotu i wykorzystania w paszach - Produkcja wysokiej jakości pasz z trwałych użytków zielonych" (program wieloletni na lata 2011-2015).

\section{REFERENCES}

AMSA. 2012. AMSA Meat Color Measurement Guidelines. American Meat Science Association Champaign, Illinois USA. $0-124$.

Cross, H. R., R. L. West and T. R. Dutson. 1981. Comparison of methods for measuring sarcomere length in beef semitendinosus muscle. Meat Sci. 5:261-266.

du Plessis, I. and L. C. Hoffman. 2007. Effect of slaughter age and breed on the carcass traits and meat quality of beef steers finished on natural pastures in the arid subtropics of South Africa. S. Afr. J. Anim. Sci. 37:143-153.

Dymnicka, M., J. Klupczyński, A. Łozicki, J. Miciński and J. Strzetelski. 2004. Polyunsaturated fatty acids in M. longissimus thoracis of fattening bulls fed silage of grass or maize. J. Anim. Feed Sci. 13 (Suppl. 2):101-104.

Guzek, D., D. Głąbska, K. Głąbski, P. Plewa, R. Plewa and A. Wierzbicka. 2012. Comparison of sarcomere length for two types of meat from animal family suidae - analysis of measurements carried out by microscopic technique. Adv. Sci. Technol. Res. J. 6:13-17.

Gwartney, B. L., C. R. Calkins, R. J. Rasby, R. A. Stock, B. A. Vieselmeyer and J. A. Gosey. 1996. Use of expected progeny differences for marbling in beef: II. Carcass and palatability. J. Anim. Sci. 74:1014-1022.

Hocquette, J. F., R. I. Richardson, S. Prache, F. Medale, G. Duffy and N. D. Scollan. 2005. The future trends for research on quality and safety of animal products. Ital. J. Anim. Sci. 4:4972.

Holló, G., J. Tőzsér, I. Hol, J. Csapó and E. Szücs. 2001b. Effect of breed, live weight on the fatty acid, amino acid content and on the biological value of beef. Act. Aliment. 30:311-322.

Holló, G., J. Csapó, E. Szucs, J. Tozser, I. Repa and I. Holló. 2001. Influence of breed, slaughter weight and gender on chemical composition of beef. Part 2. Fatty acid composition of fat in rib samples. Asian Australas. J. Anim. Sci. 14:1719-1723.

Hunt, M. C., J. C. Acton, R. C. Benedict, C. R. Calkins, D. P. Cornforth, L. E. Jeremiah, D. G., C. P. Olson Salm, J. W. Savell and S. D. Shivas. 1991. Guidelines for meat color evaluation. AMSA Committee on Guidelines for Meat Color Evaluation. National Livestock and Meat Board. Chicago, Illinois.

Indurain, G., T. R. Carr, M. V. Goñi, K. Insausti and M. J. Beriain. 2009. The relationship of carcass measurements to carcass composition and intramuscular fat in Spanish beef. Meat Sci. 82:155-161.

Janz, J. A. M., J. L. Aalhus, W. M. Robertson, M. E. R. Dugan, I. L. Larsen and S. Landry. 2004. The effects of modified carcass chilling on beef carcass grade and quality of several muscles. Can. J. Anim. Sci. 84:377-384.

Jones, S. D. M., W. M. Robertson and S. Talbot. 1992. Marbling standards for beef and pork. Agriculture and Agri-Food Canada Pub. No. 1879/E, Ottawa, ON.

Maher, S. C., A. M. Mullen, A. P. Moloney, W. Reville, D. J. Buckley, J. P. Kerry and D. J. Troy. 2005. Ultrastructural variation in beef $\mathrm{M}$. longissimus dorsi as an explanation of the variation in beef tenderness. J. Food Sci. 70:579-584.

Muchenjea, V., A. Hugo, K. Dzama, M. Chimonyo, P. E. Strydom and J. G. Raats. 2009. Cholesterol levels and fatty acid profiles of beef from three cattle breeds raised on natural pasture. J. Food Comp. Anal. 22:354-358.

Nogalski, Z. and J. Pogorzelska. 2001. Growth rate and slaughter value of heifers with different types of conformation. Natural Sci. 9:277-284.

Nuernberg, K., D. Dannenberger, G. Nuernberg, K. Ender, J. Voigt, 
N. D. Scollan, J. D. Wood, G. R. Nute and R. I. Richardson. 2005. Effect of a grass-based and a concentrate feeding system on meat quality characteristics and fatty acid composition of longissimus muscle in different cattle breeds. Livest. Prod. Sci. 94:137-147.

Pabiou, T., W. F. Fikse, A. R. Cromie, M. G. Keane, A. Nasholm and D. P. Berry. 2011. Use of digital images to predict carcass cut yields in cattle. Livest. Sci. 137:130-140.

Park, G. B., S. S. Moon, Y. D. Ko, J. K. Ha, H. H. Chang and S. T. Joo. 2002. Influence of slaughter weight and sex on yield and quality grades of Hanwoo (Korean native cattle) carcasses. J. Anim. Sci. 80:129-136.

Prevolnik, M., M. Čandek-Potokar and D. Škorjanc. 2004. Ability of NIR spectroscopy to predict meat chemical composition and quality - a review. Czech J. Anim. Sci. 49:500-510.

Priolo, A., D. Micol and J. Agabriel. 2001. Effects of grass feeding systems on ruminant meat colour and flavour. A review. Anim. Res. INRA. 50:185-200.

Scollan N., J. F. Hocquette, K. Nuernberg, D. Dannenberger, I. Richardson and A. Moloney. 2006. Innovations in beef production systems that enhance the nutritional and health value of beef lipids and their relationship with meat quality. Meat Sci. 74:17-33.
Shackelford, S. D., M. Koohmaraie and T. L. Wheeler. 1995. Effects of slaughter age on meat tenderness and USDA carcass maturity scores of beef females. J. Anim. Sci. 73:3304-3309.

Węglarz, A. 2010. Meat quality defined based on $\mathrm{pH}$ and colour depending on cattle category and slaughter season. Czech J. Anim. Sci. 55:548-556.

Wheeler, T. L., S. D. Shackelford and M. Koohmaraie. 2000. Variation in proteolysis, sarcomere length, collagen content, and tenderness among major pork muscles. J. Anim. Sci. 78:958.

Wulf, D. M., J. B. Morgan, J. D. Tatum and G. C. Smith. 1996. Effects of animal age, marbling score, calpastatin activity, subprimal cut, calcium injection, and degree of doneness on the palatability of steaks from limousin steers. J. Anim. Sci. 74:569-576.

Xie, X., Q. Meng, Z. Cui and L. Ren. 2012. Effect of cattle breed on meat quality, muscle fiber characteristics, lipid oxidation and fatty acids in China. Asian Australas. J. Anim. Sci. 25:824831.

Yang, X. J., E. Albrecht, K. Ender, R. Q. Zhao and J. Wegner. 2006. Computer image analysis of intramuscular adipocytes and marbling in the longissimus muscle of cattle. J. Anim. Sci. $84: 3251-3258$ 